\title{
What Do Web Users Know about Skin Self-Examination and Melanoma Symptoms?
}

\author{
Grażyna Kamińska-Winciorek ${ }^{1 *}$, Maksymilian Gajda², Jerzy Wydmański³ \\ Andrzej Tukiendorf ${ }^{4}$
}

\begin{abstract}
Background: Skin self-examination (SSE) may facilitate early diagnosis of melanoma at a potentially curable stage. Little data are available concerning the SSE frequency and knowledge about the symptoms of melanoma in non-patient populations. The aim of our study was to assess the performance of skin self-examination, recognition of potential melanoma symptoms as well as behavior related to sun exposure among web users in Poland. Materials and Methods: A cross-sectional study was conducted among readers of a scientific portal. Invited respondents were asked to complete an online questionnaire. Finally, statistical analysis was conducted on 4,919 surveys towards potential clinical signs of melanoma and SSE performance. Results: Approximately $60 \%$ of respondents had ever performed SSE in their life. Only $18.4 \%$ declared performance on a regular, monthly, basis. Factors promoting this activity were established to be bigger place of residence, higher education and sensitive skin phototype, higher level of knowledge concerning melanoma, safe tanning rules and, especially, past surgical excision of naevi. Declared longer use of tanning beds was linked to understanding better the importance of clinical features of melanoma. Awareness of hazardous behavior during sunbathing is associated with the attempts to change them. Conclusions: Regular SSE is not a common practice, whilst the knowledge about the clinical features of melanoma is varied. Therefore, constant pressure should be put on promotion of regular skin self-examination and teaching its proper techniques, including familiarity with the $\mathrm{ABCD}$ (asymmetry; border; color; diameter) rule and its extension of "EFG" (elevated, firm, progressive growth) criteria.
\end{abstract}

Keywords: skin self-examination - melanoma awareness - symptoms, pink lesion - ABCD rule - EFG rule

Asian Pac J Cancer Prev, 16 (7), 3051-3056

\section{Introduction}

Along the reported and predicted global increase of melanoma incidence, the efforts to improve the early detection of this dangerous disease are still needed (Ferlay et al.,2013). As the primary lesion's wide surgical excision is the main method of treatment, the early diagnosis of locally advanced melanoma is associated with a much better prognosis (American Cancer Society, 2013).Among the patients with $0.01-0.5 \mathrm{~mm}$ thick melanoma, the 10 -year survival is $96 \%$, while for patients with tumor thickness greater than $6 \mathrm{~mm}$, the 10-year survival rate is decreased to $42 \%$ (Edge et al., 2013). Having thinner tumors was associated with performing routine skin self-examination (SSE) and the assistance of pictures in the demonstration of melanoma's clinical appearance (Swetter et al., 2012).

SSE for new melanocytic lesions or change in appearance of these already present may facilitate early diagnosis of the disease in potentially curable stage (Weinstock, 2006). Although at different frequencies, SSE is performed by the majority of patients diagnosed with melanoma or atypical melanocytic lesions (Hull et al., 2011). Little data is available concerning the SSE frequency in non-patient population. Unfortunately, these available highlighted that both SSE and skin examination performed by partner are an uncommon practice (Weinstock et al., 1999). The aim of our study was to assess the attitude towards the skin self-examination, recognition of potential melanoma symptoms and behaviors related to sun exposure.

\section{Materials and Methods}

A dedicated web-based questionnaire was designed and a cross-sectional study was conducted among readers of a Polish scientific portal.

\section{Data acquisition and study population}

Acquisition of the respondents' answers to the questionnaire was conducted from March 2, 2012 to June 1, 2012. After answering all of the required questions, the responses were saved in a spreadsheet.

${ }^{1}$ The Center for Cancer Prevention and Treatment, Katowice, ${ }^{2}$ Clinical Oncology Ward, Starkiewicz Specialised Hospital, Dabrowa, ${ }^{3}$ Department of Conventional and Intraoperative Radiotherapy, Branch, ${ }^{4}$ Department of Epidemiology, Maria Sklodowska-Curie Memorial Cancer Centre and Institute of Oncology, Gliwice Branch, Poland *For correspondence: dermatolog.pl@gmail.com 
Grażyna Kamińska-Winciorek et al

The Google Docs platform (http://docs.google.com/) was used for preparation and storage of the data. No data were stored that were likely to identify the respondents (e.g., IP addresses). The participants answered questions autonomously via a web browser. To reduce the risk of multiple participation by the same respondent, so-called 'cookies' were used, which allowed the storage of a declared consent to participate (or the absence of such approval). Each participant was informed about the purpose and the anonymous character of the survey.

The examined group of respondents consisted of 4,919 individuals in median age of 29.4, ranges from 11 to 92 years, 968 males and 3,951 females. Most of the interviewees $(74.9 \%)$ lived in town. Almost every tenth respondent $(10.8 \%)$ was an inhabitant of a town having less than twenty thousand of people. Towns with number of citizens ranging from 20 to 200 thousands were represented by $24.3 \%$ of surveyed. Cities with more than five hundred thousand of residents were inhabited by near quarter of surveyed (25.9\%). Forty-seven point four percent of questioned declared to be the highest educated (master's degree and beyond). The other numerous group of respondents declared to have completed the high school
( $10.2 \%$ having first and $37.9 \%$ with second degree). Poor education concerned only a small percent of the interviewees with $1.9 \%$ having no formal education and $2.7 \%$ reporting to have accomplished only the elementary school.

\section{Structure of the e-questionnaire}

The self-completion, user-friendly, web-based questionnaire contained a total of 61 questions that were mainly closed-ended (47 questions, Q). The questions were written in Polish and were divided into three different subsets related to demographic data, primary prevention responses, and secondary prevention. The respondents were asked about clinical types and symptoms that might indicate the development of melanoma.

\section{Ethical issues}

The Institutional Review Board from the Cancer Centre and Institute of Oncology in Gliwice (Poland) stated that this research did not require their approval.

\section{Statistical analysis}

The statistical analysis was conducted on fully

\section{Table 1. Performance of Skin Self-Examination}

\begin{tabular}{|c|c|c|c|}
\hline \multicolumn{4}{|l|}{ Q50 Do you perform the self-examination of your skin } \\
\hline Predictors & OR & CI $95 \%$ & $\mathrm{P}$ \\
\hline Q10 Do you regularly use sunscreen creams while sunbathing? & 1.26 & $(1.09,1.46)$ & 0.002 \\
\hline Q13 Do you repeat application of sunscreen cream during one sunbathe session? & 1.21 & $(1.04,1.41)$ & 0.012 \\
\hline Q15 Do you apply sunscreen cream after each out of the water? & 1.17 & $(1.01,1.37)$ & 0.036 \\
\hline Q20 Do you choose a sunscreen cream based on the SPF: PPD factor? & 1.31 & $(1.15,1.5)$ & $<0.001$ \\
\hline Q28 Do you usually wear a special eye-glasses in a tanning bed? & 1.16 & $(1.02,1.31)$ & 0.02 \\
\hline $\begin{array}{l}\text { Q30 Do you know that the history of sunburns increase the risk of melanoma up to five } \\
\text { times? }\end{array}$ & 1.55 & $(1.33,1.82)$ & $<0.001$ \\
\hline Q32 How many times have you experienced a sunburn before the age of $18 ?$ & 0.98 & $(0.96,0.99)$ & 0.002 \\
\hline $\begin{array}{l}\text { Q33 Can you divide the skin into the phototypes depending on the response of skin to } \\
\text { the sunlight: sunburn and the appearance of a tan? }\end{array}$ & 1.63 & $(1.44,1.86)$ & $<0.001$ \\
\hline Q37 Did you know that melanoma is one of the most malignant cancer? & 1.63 & $(1.36,1.95)$ & $<0.001$ \\
\hline \multicolumn{4}{|l|}{$\begin{array}{l}\text { Q51 Do you regularly observe the skin of the whole body in search of new and old } \\
\text { pigmented moles? }\end{array}$} \\
\hline Q3 Place of residence & 1.057 & $(1.02,1.095)$ & 0.0011 \\
\hline Q4 Education - school completed & 1.158 & $(1.088,1.233)$ & $<0.001$ \\
\hline Q13 Do you repeat application of sunscreen cream during one sunbathe session? & 0.811 & $(0.727,0.905)$ & 0.0001 \\
\hline Q20 Do you choose a sunscreen cream based on the SPF: PPD factor? & 0.773 & $(0.692,0.862)$ & $<0.001$ \\
\hline $\begin{array}{l}\text { Q30 Do you know that the history of sunburns increase the risk of melanoma up to five } \\
\text { times? }\end{array}$ & 0.69 & $(0.598,0.796)$ & $<0.001$ \\
\hline $\begin{array}{l}\text { Q33 Can you divide the skin into the phototypes depending on the response of skin to } \\
\text { the sunlight: sunburn and the appearance of a tan? }\end{array}$ & 0.769 & $(0.685,0.862)$ & $<0.001$ \\
\hline Q34 How would you describe your skin phototype? & 0.867 & $(0.8,0.939)$ & $<0.001$ \\
\hline Q37 Did you know that melanoma is one of the most malignant cancer? & 0.771 & $(0.651,0.913)$ & 0.0013 \\
\hline $\begin{array}{l}\text { Q39 Have you ever used the advice of dermatologist or other medical specialties on the } \\
\text { evaluation of the so-called pigmented moles? }\end{array}$ & 0.592 & $(0.527,0.664)$ & $<0.001$ \\
\hline $\begin{array}{l}\text { Q58 Would you consider examining your naevi (clinically, dermoscopic examination) } \\
\text { after filling in this questionnaire? }\end{array}$ & 0.474 & $(0.412,0.545)$ & $<0.001$ \\
\hline Q59 Have you ever had any naevi excised surgically? & 0.38 & $(0.334,0.432)$ & $<0.001$ \\
\hline
\end{tabular}


completed questionnaires using multivariate logistic regression with the $\mathrm{R}$ software ( $\mathrm{R}$ Core Team, 2013). Interpretation of the results was based classically on the odds ratio (OR) and $95 \%$ confidence intervals (CI). The statistically significant $(\mathrm{p}<0.05)$ results are reported.

\section{Results}

The data regarding the skin self-examination, recognition of potential clinical symptoms of melanoma development, behaviors related to sun exposure as well as preventive influence of the questionnaire survey (measured by the respondents' willingness to undergo a medical examination, including dermoscopy after completing the survey) are presented (Tables 1-3).

\section{Overall presentation of the data concerning respondents' awareness}

The majority of respondents $(94.5 \%)$ were of the opinion that regular sunlight exposure increases the risk of melanoma. Fairly common awareness that a history of sunburns increases the risk of melanoma up to five fold (78.6\% of respondents) was observed. Only $46.4 \%$ surveyed declared to use sunscreens regularly, whilst slightly fewer $(44.2 \%)$ applied them after swimming. Two thirds $(65.6 \%)$ of questioned stated that they like sunbathing, meanwhile $18.8 \%$ reported to use tanning beds.

\section{Skin self-assessment for detection of melanoma}

Performing SSE (Q50) was more highly associated with regular use of a sunscreen creams and reapplying them during sunbathing as well as after swimming. Respondents performing SSE more frequently were choosing a sunscreen cream based on the SPF: PPD factor and also wore protective eyeglasses more regularly when using tanning beds. The performance of skin selfexamination was highly associated with the awareness that a history of sunburns increases the risk of melanoma, knowledge that melanoma was one of the most malignant types of cancer as well as acquaintance with the skin phototypes. The occurrence of sunburn before the age of 18 was also less often reported among individuals ever performing SSE (Q50, Table 1).

The regular skin assessment was more often performed by individuals who lived in more populous areas, were better educated and had more sensitive skin phototype. The statistically significant, positive relationship between past surgical excision of a naevi and current regular SSE performance was found. Those performing SSE habitually declared to choose a sunscreen cream based on the SPF: PPD factor and more frequently reapplied such creams during sunbathing sessions as well as were more likely to seek for a medical advice. In addition, they declared significantly more often to consider having their naevi examined after participation in our study, compared with these not taking care of the skin lesions (Q51, Table 1).

\section{Knowledge of potential clinical symptoms of melanoma}

Type of color (C) and dynamics (D2) of lesion's morphological changes proved to be the most recognizable clinical ABCDE symptoms (78\% and 63.5\%, respectively). Other clinical features such as asymmetry (A) and diameter $(\mathrm{D} 1)>5 \mathrm{~mm}$ were recognized among only slightly over half of the respondents $(55.9 \%$ and $56.1 \%$, respectively). The sensory disturbances (e.g., itching and paraesthesia) proved to be the least known alarming symptoms (knowledge declared by $48.9 \%$ surveyed) while $84.3 \%$ were aware of change in color importance.

Respondents who knew that clinical feature $\mathrm{C}$ defined as a change of lesion's color is worrying and could indicate the development of melanoma more frequently chose a

Table 2. Attitute to the Symptoms of Melanoma and Behavior Related to Sun-Exposure

\begin{tabular}{|c|c|c|c|}
\hline $\begin{array}{l}\text { Q52D2 Which features do you think are worrying and may indicate the development of mela- } \\
\text { noma- D2) dynamics of morphological changes in the lesion }\end{array}$ & & & \\
\hline \multicolumn{1}{|c|}{ Predictors } & OR & CI 95\% & P \\
\hline $\begin{array}{l}\text { Q16 Do you choose a sunscreen cream based on the value of the UVB factor - SPF (sun } \\
\text { protection factor)? }\end{array}$ & 1.16 & $(1,1.33)$ & 0.043 \\
\hline Q32 How many times have you experienced sunburn before the age of 18? & 1.02 & $(1.01,1.04)$ & 0.009 \\
\hline $\begin{array}{l}\text { Q53C Which features do you think are worrying and may indicate the development of } \\
\text { melanoma C) change in color }\end{array}$ & & & \\
\hline Q20 Do you choose a sunscreen cream based on the SPF: PPD factor? & 0.83 & $(0.7,0.98)$ & 0.028 \\
\hline Q32 How many times have you experienced sunburn before the age of 18? & 1.03 & $(1.01,1.05)$ & 0.014 \\
\hline Q8 Do you like sunbathing outside? & 0.86 & $(0.76,0.98)$ & 0.027 \\
\hline $\begin{array}{l}\text { Q53F Which features do you think are worrying and may indicate the development of } \\
\text { melanoma F) sensory disturbance (e.g., itching, and paraesthesia) }\end{array}$ & & \\
\hline Q6 How long (during a day) do you usually work outdoors? & 0.96 & $(0.93,0.99)$ & 0.01 \\
\hline Q8 Do you like sunbathing outside? & 0.86 & $(0.76,0.98)$ & 0.027 \\
\hline $\begin{array}{l}\text { Q54C Which of the above would lead you to the dermatological consultation and dermo- } \\
\text { scopic evaluation C) The appearance of a pink nodule }\end{array}$ & & 1.18 & $(1.03,1.36)$ \\
\hline $\begin{array}{l}\text { Q16 Do you choose a sunscreen cream based on the value of the UVB factor - SPF (sun } \\
\text { protection factor)? }\end{array}$ & 0.017 \\
\hline Q32 How many times have you experienced sunburn before the age of 18? & 1.02 & $(1,1.03)$ & 0.017 \\
\hline
\end{tabular}




\begin{tabular}{|c|c|c|c|}
\hline $\begin{array}{l}\text { Q58 Would you visit a doctor for have your signs examined after filling in this } \\
\text { questionnaire (clinically, dermoscopic examination)? }\end{array}$ & & & \\
\hline Predictors & OR & CI $95 \%$ & $\mathrm{P}$ \\
\hline Q1 Your age (years) & 1.02 & $(1.01,1.03)$ & $<0.001$ \\
\hline Q4 Education - school completed & 1.22 & $(1.12,1.33)$ & $<0.001$ \\
\hline Q10 Do you regularly use sunscreen creams while sunbathing? & 1.51 & $(1.25,1.81)$ & $<0.001$ \\
\hline Q11 If you use a sunscreen creams - tick since how many years & 0.99 & $(0.98,1)$ & 0.031 \\
\hline $\begin{array}{l}\text { Q16 Do you choose a sunscreen cream based on the value of the UVB factor - SPF (sun } \\
\text { protection factor)? }\end{array}$ & 1.63 & $(1.34,1.98)$ & $<0.001$ \\
\hline Q17 What is the value of SPF used by you? & 0.9949 & $(0.99,0.9998)$ & 0.04 \\
\hline Q20 Do you choose a sunscreen cream based on the SPF: PPD factor? & 1.34 & $(1.14,1.59)$ & $<0.001$ \\
\hline Q26 For how many years have you been using tanning bed regularly? & 1.05 & $(1.01,1.1)$ & 0.016 \\
\hline Q37 Did you know that melanoma is one of the most malignant cancer? & 1.39 & $(1.15,1.68)$ & $<0.001$ \\
\hline
\end{tabular}

sunscreen cream based on the value of UVA factor or anti-UVA-PPD, and also had been sunburned more often before the age of 18 (Q53C, Table 2).

Individuals aware of D2 (dynamics) clinical feature importance (defined as morphological changes in the lesion) expressed as potential indicator of the melanoma development were more frequently choosing sunscreens based on the value of the UVB factor - SPF. In addition, sunburns before the age of 18 were more common in this group of respondents (Q52D2, Table 2).

Individuals perceiving sensory disturbances (e.g. itching, and paraesthesia) regarding the lesion as threatening and potential indicator of the development of melanoma (Q53F, Table 2) much less liked sunbathing outdoors as well as used to work outdoors proportionally longer daily.

Respondents who indicated that the presence of a pink nodule would lead them to the dermatological consultation were choosing a sunscreen based on the UVB factor value - SPF more frequently and were more likely to be sunburned before the age of 18 (Q54C, Table 2).

\section{Pro-health impact of taking part in the survey}

Individuals who declared to consider having their skin examined (clinically or dermoscopically) after filling in this questionnaire study were more often older, better educated, chose sunscreens creams based on the SPF: PPD factor as well as used them more regularly during sunbathing. Representatives of this group more frequently were aware of the malignant nature of melanoma. Unfortunately, these surveyed had been using tanning beds for more years and sunscreens with lower SPF values, which had been applied for a shorter period of time (summary in years) (Q58, Table 3).

\section{Discussion}

As little is known about awareness, behaviors and does associated with SSE among non-patient population and only few papers were published concerning selected groups, therefore our aim was to perform such an evaluation (Al-Naggar et al., 2011; Andsoy et al., 2013; Walton et al., 2014).
The limitations of this study included: restricted sampling associated with having an internet access (62\% of Polish citizens over the age of 15) and the need for the sufficient internet skills among surveyed (World Internet Project: Polska, 2013). Moreover, the nonresponse bias can not be excluded.

Overlooking the changes in existing or ignoring new skin lesions was stated to be the main reasons for the patient-related delay of diagnosis (Gajda and Kaminska-Winciorek, 2014). Unfortunately patients' attention was mostly paid to the late signs of melanoma such as presence of ulceration or bleeding (Krige et al., 1991). It was stated that patients who have no training in performing SSE were able to detect between $44-57 \%$ of melanomas (McPherson et al., 2006). Clinical "ABCD" (Asymmetry; Border; Color; Diameter) algorithm was reported to improve SSE sensitivity to $57-90 \%$ and the specificity to 59-90\% (Rigel et al., 2010). Results coming from teaching with the use of photographs could be more efficient than these achieved with "ABCD" criteria (Grob and Richard, 2004). Our study showed that the best known symptom of melanoma was change in color (more than three quarters of respondents) whereas, quite surprisingly, the worst recognition concerned the asymmetry (slightly more than half of the surveyed) and especially sensory disturbances with report's frequency of $48.9 \%$. As some melanomas do not meet basic clinical "ABCD" criteria (nodular, amelanotic melanoma occurring commonly as a pink nodular lesion) and even can mimic benign lesions leading to misdiagnosis and inappropriate treatment, it appears that the acquaintance with the additional criteria forming in the acronym "EFG" (elevated, firm, >1 month progressive growth) is advisable (Chamberlain et al., 2003; Giacomel et al., 2008). Taking into an account the fact that even clinical examination extended with dermoscopic evaluation does not provide $100 \%$ accuracy of melanoma diagnosis, therefore in such suspicious lesions cases, especially meeting the criteria of the EFG, the executing the excisional biopsy with subsequent histological examination seems to be required (Giacomel et al., 2008).

"Pink nodule" could be an alarming symptom, suggesting the probability of melanoma presence (Rader 
et al., 2014). Part of our respondents were aware of that and proved their high knowledge in that way. They also relied on SPF value when choosing sunscreens. What's even more interesting, sunburns before the age of 18 had occurred slightly more frequent in this group (compared with those unaware of the pink nodule importance). As shown above, the same regularity occurred among individuals having knowledge of the clinical signs of $\mathrm{C}$ and D. On the other hand, surveyed who indicated sensory disturbances as the important symptoms that may suggest melanoma presence showed a lower propensity for sunbathing and outdoor work.

The importance of SSE is high, particularly for the detection of nodular melanoma, which is characterized by rapid growth between consecutive doctor's clinical examinations (Chamberlain et al., 2003). The overall impression of irregularities, the "ugly duckling" sign and a recent change of lesion are the most useful symptoms for melanoma recognition (Grob and Richard, 2004; Scope et al., 2008). Nearly two-thirds of our respondents $(60.6 \%)$ declared to have performed SSE at least once in their life while $18.4 \%$ were examining their skin regularly (once a month). While recommendations for the frequency of skin self-examination are not unified, most authors recommend its monthly conducting (Goodson and Grossman, 2009). Our study established that bigger place of residence, education and having more sensitive skin phototype are SSE-promoting factors. Also the positive correlation between carrying out regular examination and the knowledge concerning melanoma and safe tanning rules was demonstrated. In Australia and United States (USA) not more than every fourth individual performs skin self-examination on a regular basis (Aitken et al., 2004; Weinstock et al., 2007). Recent study demonstrated the frequency of SSE to be similar in the group with no history of melanoma (28.1 and $30.7 \%$ of males and females, respectively) and slightly greater among individuals with positive family history of melanoma (36.5 and $43.6 \%$ of males and females, respectively) (Kasparian et al., 2012).

Most of surveyed were aware of the risks associated with sun exposure. Unfortunately, this awareness is not always associated with the regular use of sunscreen protection. Surveyed who had used the tanning beds often and had been applying sun protecting creams for shorter period of time, in addition with a lower SPF. Currently being better educated, they are aware of the threat posed by melanoma and declare more health-promoting behaviors related to sun exposure. Our research shows that this group of people is likely to consider examination of their skin and also use sunscreens based on the value of the SPF: PPD indicator regularly. The awareness of hazardous behaviors during sunbathing is associated with the attempts to change them. Surprisingly, declared longer use of tanning beds was related to the better understanding of the clinical features of melanoma. The frequency of regular SSE in studied population seems to be slightly lower compared with Australia or USA. The significant positive relationship between past surgical excision of a naevi and current regular SSE performance was demonstrated. Other identified SSE-promoting factors are: place of residence, education and skin phototype.
Moreover, positive correlation between the regular skin assessment and the knowledge concerning melanoma and safe tanning rules was demonstrated. The occurrence of a sunburn before the age of 18 was less likely in people who reported to perform SSE.

Educational campaigns aimed at raising awareness about melanoma and skin self-examination favor the diagnosis of tumors of smaller thickness (Mitchell and Leslie, 2013). The use of interactive patients' training in combination with teaching practical SSE techniques could improve the efficiency of self-examination maintained by patients (Aneja et al., 2012). Another solution which might have an influence on the skin self-examination improvement may be the use of e-Health services, including the use of mobile devices (Tyagi et al., 2012). We can assume that also our study motivated surveyed to check their lesions as more than $80 \%$ of them stated to consider having their skin examined (clinical or dermoscopic evaluation).

In conclusion, the knowledge about the clinical features of melanoma is varied. Moreover, monthly performig skin self-examination is uncommon. Therefore, constant pressure should be put on the promotion of conducting regular self-examination of the skin and teaching its proper techniques, including familiarity with the ABCD rule and its extension of "EFG" criterion. It is also important to adapt new methods that use technological advances in the screening for melanoma.

\section{References}

Aitken JF, Janda M, Lowe JB, et al (2004). Prevalence of wholebody skin self-examination in a population at high risk for skin cancer (Australia). Cancer Causes Control, 15, 453-63.

Al-Naggar RA, Al-Naggar TH, Bobryshev YV (2011). Perceptions and opinions towards skin cancer prevention in Malaysia: A Qualitative Approach. Asian Pac J Cancer Prev, 12, 995-9.

American Cancer Society. Cancer Facts and Figures (2013). Atlanta: American Cancer Society; 2013. Available at: http://www.cancer.org/acs/groups/content/@ epidemiologysurveilance/documents/document/ acspc-036845.pdf (accessed: 22 June 2014)

Andsoy II, Gül A, Sahin AO, Karabacak H (2013). What Turkish nurses know and do about skin cancer and sun protective behavior. Asian Pac J Cancer Prev, 14, 7663-8.

Aneja S, Brimhall AK, Kast DR, et al (2012). Improvement in patient performance of skin self-examinations after intervention with interactive education and telecommunication reminders: a randomized controlled study. Arch Dermatol, 148, 1266-72.

Chamberlain AJ, Fritschi L, Kelly JW (2003). Nodular melanoma: patients' perceptions of presenting features and implications for earlier detection. J Am Acad Dermatol, 48, 694-701.

Edge SB, Byrd DR, Compton C, et al (2010). AJCC cancer staging manual. melanoma of the skin. 2010. Springer, New York, Dordrecht, Heildeberg, London.

Ferlay J, Soerjomataram I, Ervik M, et al (2013). GLOBOCAN 2012 v 1.0, Cancer Incidence and Mortality Worldwide: IARC CancerBase No. 11. Lyon, France: International Agency for Research on Cancer. 2013. Available at: http:// globocan.iarc.fr (accessed 24 March 2014).

Gajda M, Kaminska-Winciorek G (2014). Do not let to be late: 
overview of reasons for melanoma delayed diagnosis. Asian Pac J Cancer Prev, 15, 3873-7.

Giacomel J, Zalaudek I, Mordente I, Nicolino R, Argenziano G (2008). Never perform laser treatment of skin tumors with clinical "EFG" criteria. J Dtsch Dermatol Ges, 6, 386-8.

Goodson AG, Grossman D (2009). Strategies for early melanoma detection: approaches to the patient with nevi. J Am Acad Dermatol, 60, 719-35.

Grob JJ, Richard MA (2004). Epidemiology and prevention of melanoma. Rev Prat, 54, 1181-6.

Hull PR, Piemontesi NG, Lichtenwald J (2011). Compliance with self-examination surveillance in patients with melanoma and atypical moles: an anonymous questionnaire study. J Cutan Med Surg, 15, 97-102.

Kasparian NA, Branstrom R, Chang YM, et al (2012). Melanoma genetics consortium (GenoMEL). Skin examination behavior: the role of melanoma history, skin type, psychosocial factors, and region of residence in determining clinical and self-conducted skin examination. Arch Dermatol, 148, 1142-51.

Krige JE, Isaacs S, Hudson DA, et al (1991). Delay in the diagnosis of cutaneous malignant melanoma. A prospective study in 250 patients. Cancer, 68, 2064-8.

McPherson M, Elwood M, English DR, et al (2006). Presentation and detection of invasive melanoma in a high-risk population. J Am Acad Dermatol, 54, 783-92.

Mitchell JK, Leslie KS (2013). Melanoma death prevention: moving away from the sun. J Am Acad Dermatol, 68, 169-75.

R Core Team. R (2013): A language and environment for statistical computing. R Version 3.0.2. Vienna: R Foundation for Statistical Computing. Available at: http://cran.r-project. org. Accessed 20 September 2013.

Rader RK, Payne KS, Guntupalli U, et al (2014). The pink rim sign: location of pink as an indicator of melanoma in dermoscopic images. J Skin Cance, 2014, 719740.

Rigel DS, Russak J, Friedman R (2010). The evolution of melanoma diagnosis: 25 years beyond the ABCDs. $C A$ Cancer J Clin, 60, 301-16.

Scope A, Dusza SW, Halpern AC, et al (2008). The "ugly duckling" sign: agreement between observers. Arch Dermatol, 144, 58-64.

Swetter SM, Pollitt RA, Johnson TM, Brooks DR, Geller AC (2012). Behavioral determinants of successful early melanoma detection: role of self and physician skin examination. Cancer, 118, 3725-34.

Tyagi A, Miller K, Cockburn M (2012). e-Health Tools for targeting and improving melanoma screening: a review. $J$ Skin Cancer, 2012, 437502.

Walton AE, Janda M, Youl PH, et al (2014). Uptake of skin selfexamination and clinical examination behavior by outdoor workers. Arch Environ Occup Health, 69, 214-20.

Weinstock MA, Martin RA, Risica PM, et al (1999). Thorough skin examination for the early detection of melanoma. Am J Prev Med, 17, 169-75.

Weinstock MA (2006). Cutaneous melanoma: public health approach to early detection. Dermatol Ther, 19, 26-31.

Weinstock MA, Risica PM, Martin RA, et al (2007). Melanoma early detection with thorough skin self-examination: the "check it out" randomized trial. Am J Prev Med, 32, 517-24.

World Internet Project: Polska. 2013. Available at: http:// bi.gazeta.pl/im/5/14910/m14910615, Raport-Wip2013.pdf (accessed 22 January 2014) 